\title{
Author Correction: Kondo-like transport and magnetic field effect of charge carrier fluctuations in granular aluminum oxide thin films
}

\author{
C. Barone $\mathbb{D}^{1}$, H. Rotzinger ${ }^{2}$, C. Mauro ${ }^{1,3}$, D. Dorer ${ }^{2}$, J. Münzberg ${ }^{2}$, A. V. Ustinov ${ }^{2,4}$ \& S. Pagano $\mathbb{D}^{1}$ \\ Correction to: Scientific Reports https://doi.org/10.1038/s41598-018-32298-1, published online 17 September \\ 2018
}

The Acknowledgements section in this Article in incomplete.

"S. Abate of CNR-SPIN Salerno is acknowledged for his valuable technical support. This work is partially supported by University of Salerno through grants FARB15PAGAN and FARB16CAVAL."

should read:

"S. Abate of CNR-SPIN Salerno is acknowledged for his valuable technical support. This work is partially supported by University of Salerno through grants FARB15PAGAN and FARB16CAVAL.

A.V.U. acknowledges partial support from the Ministry of Education and Science of the Russian Federation in the framework of Increase Competitiveness Program of the National University of Science and Technology MISIS (Contract No. K2-2017-081)."

(i) Open Access This article is licensed under a Creative Commons Attribution 4.0 International License, which permits use, sharing, adaptation, distribution and reproduction in any medium or format, as long as you give appropriate credit to the original author(s) and the source, provide a link to the Creative Commons license, and indicate if changes were made. The images or other third party material in this article are included in the article's Creative Commons license, unless indicated otherwise in a credit line to the material. If material is not included in the article's Creative Commons license and your intended use is not permitted by statutory regulation or exceeds the permitted use, you will need to obtain permission directly from the copyright holder. To view a copy of this license, visit http://creativecommons.org/licenses/by/4.0/.

(C) The Author(s) 2018

\footnotetext{
${ }^{1}$ Dipartimento di Fisica "E.R. Caianiello" and CNR-SPIN Salerno, Università di Salerno, I-84084, Fisciano, Salerno, Italy. ${ }^{2}$ Physikalisches Institut, Karlsruhe Institute of Technology, 76131, Karlsruhe, Germany. ${ }^{3}$ Dipartimento di Ingegneria, Università del Sannio, I-82100, Benevento, Italy. ${ }^{4}$ Russian Quantum Center, National University of Science and Technology MISIS, 119049, Moscow, Russia. Correspondence and requests for materials should be addressed to C.B. (email: cbarone@unisa.it)
} 